\title{
Unifying Efforts to Rebound Operational Excellence and Export Competitiveness
}

\author{
Sourabh D. Kulkarni ${ }^{1}$ (D) S. G. Deshmukh ${ }^{2}$ (D) Vivek V. Khanzode ${ }^{3}$ (i) $\cdot$ Anabela C. Alves $^{4}$ (D)
}

Received: 10 October 2021 / Accepted: 14 November 2021 / Published online: 17 December 2021

(c) The Author(s) under exclusive licence to Global Institute of Flexible Systems Management 2021

\begin{abstract}
COVID-19 pandemic have provided us an opportunity to retrospect, our traditional practices, operations, supply chain functions and their linkages with firm competitiveness. The recovery to the new normal of operational excellence is the challenging task ahead. The critical a question in post-pandemic recovery can be-How can the firms rebound to operational excellence and achieve the benchmarks of international competitiveness with the current uncertainties in both demand and supply sides? Trigger the thinking on the challenging issue, we had invited the scholarly articles, empirical studies, reviews and perspective papers based on the theme "Rebound to Higher Levels of Operational Excellence and Export competitiveness". This work presents the editorial summary of the special issue and suggest pathways and possible research and managerial, policy level directives towards the Operational Excellence and Export competitiveness. The study utilizes three specific inputs- (a) Academic resources, (b) Industrial Discourse and (c) International trade and Government initiatives to present the directives for further research interventions. While, this multi-perspective consideration does not represent the comprehensive systematic literature review or the empirical research, but it enables us to explore the challenges, enablers and decision-making approaches for rebounding operational excellence towards export competitiveness.
\end{abstract}

Keywords Operational excellence $\cdot$ Export competitiveness $\cdot$ Operations strategy $\cdot$ Rebound from COVID-19 $\cdot$ Leanagile operations · Atma-Nirbharta and service exports · Resilient supply chains $\cdot$ Humanitarian logistics $\cdot$ Modern service systems $\cdot$ Manufacturing flexibility

Sourabh D. Kulkarni

sourabh.kulkarni@fsm.ac.in

S. G. Deshmukh

deshmukh@mech.iitd.ac.in

Vivek V. Khanzode

vkhanzode@nitie.ac.in

Anabela C. Alves

anabela@dps.uminho.pt

1 Quantitative Techniques and Operations Management Area, FORE School of Management, New Delhi, India

2 Department of Mechanical Engineering, Indian Institute of Technology Delhi, New Delhi, India

3 Operations and Supply Chain Management, National Institute of Industrial Engineering (NITIE), Mumbai, India

4 Department of Production and Systems, School of Engineering University of Minho, Braga, Portugal

\section{The Genesis}

\section{COVID-19 Pandemic: Opportunity to Rethink Best Practices of Operations and Supply Chain}

Modern Managers are used to rely on the operational best practices like lean, just-in-time (JIT), total quality management (TQM), total preventive maintenance (TPM) to address the competitive challenges. Generally, companies face significant surge or decline in demand, and managers adopt such best practices to dwindle operating resources and capabilities towards their competitiveness (Kulkarni et al., 2019).

The COVID-19 pandemic has magnified global supply chain challenges and has accelerated disruptions across the globe. This has also motivated me to have a relook at the operational practices of manufacturers and service providers resulting in digital transformations across a variety of sectors to respond to these abrupt market changes and become more flexible, agile, productive, and resilient operationally. 
With COVID-19 pandemic, the operational challenges of modern operations and supply chains are much darker than the expected (Deshmukh \& Haleem, 2020). This dark side has three specific folds on the background of Precautionary lockdowns- First manufacturing facilities are forced to shut down. Second, the supply-logistics channels are derailed due to transport restrictions. Third, the supply chain systems are diverted to the emergency needs, thus transportation of industrial supplies is often traded-off. Additionally, the bullwhip effect of the supply chain may enforce challenging demand-supply imbalance across the several value chains. For example, recent semiconductor chip (Chip Famine-2021 ${ }^{1}$ ) shortages in India in September 2021 due to COVID-19 lockdowns in East Asian countries, Heavy congestion in south China in the initial two quarters of 2021. The acute chip shortage has increased the order-lead time (time taken for delivery of the goods) to 50 days from 28 to 30 days, with additional 7-8 times freight cost and seriously jittered production schedules of leading Automobile firms such as Tata Motors, Maruti Suzuki, Mahindra and Mahindra.

The supply chain systems and process of the firms are designed and developed for normal operating conditions, not for such unprecedented once-in-a lifetime disruption and recovery (Simchi-Levi, 2020), iterating- "Even now the business climate... remains deeply unpredictable... the supply chain leaders should act now to plot their comeback". (Simchi-Levi, 2020).

The recovery to the new normal of operational excellence is the challenging task ahead. Needless to say, immediate operational solutions such as Best practices requires critical re-thinking as operational excellence pathway with respect to the following issues:

(i) Futile Zero inventory, offshoring tactics and extended International supply chains on the advent of Serious inventory shortages,

(ii) Reliance on the low-cost suppliers with supply chain integration across low-cost manufacturing countries,

(iii) Method and time study bounded operating lines with mechanization of Human minds.

Thus the most ultimate, critical and widely sought after question would be- How can the firm rebound to operational excellence and achieve the benchmarks of international competitiveness with the current uncertainties in both demand and supply sides?

\footnotetext{
${ }^{1}$ Global Chip Shortage impacting Indian automotive industry and festive season sale https://timesofindia.indiatimes.com/business/ india-business/semiconductor-shortages-gives-car-industry-the-jitte rs-ahead-of-festivals/articleshow/85836699.cms.
}

Outbreak or disruptions have major or long-lasting impact on the businesses, thus, it is vital to identify potential recovery challenges and their mitigation plans to execute the resurgence. The purpose of this work is to:

(a) To present the editorial of Special Issue on Rebound to Higher Levels of Operational Excellence and Export competitiveness of JGBC

(b) To suggest pathways and possible research/ managerial directions towards the Operational Excellence and Export competitiveness.

Specifically, the objectives of this editorial are as follows:

(i) Establish need for research interventions in the operational excellence and Export competitiveness studying Academic Resources and their efforts.

(ii) Summarize the existing reconfiguration efforts in Operations and Supply Chain Fields referring to Industrial Discourse of Operational excellence and allied practices.

(iii) Identify the opportunities for impactful and relevant empirical and event-based research to mitigate gap between academic research and industrial practices.

While, this multi-perspective consideration in the editorial paper does not represent the comprehensive systematic literature review or the empirical research but This editorial can assist in exploring the challenges, enablers and decision making approaches for rebounding operational excellence towards export competitiveness.

The research in field requires the more empirical, investigative studies than just presenting conceptualizing models. COVID-19 and pandemic disruptions have highlighted the need for more action-oriented research focusing on pragmatic themes of new world order such as Supply Chain complexity, Resilient Supply Chain, Digital Manufacturing, Risk Mitigations in OSCM. More importantly, competitive priorities of the firms have evolved beyond cost-competitiveness, encompassing the value of flexibility, shorter lead times, sustainability and dynamic capabilities.

\section{The Approach}

In order to achieve this, we have used the inputs from three resources- (i) Academic resources, (ii) Industrial Discourse and (iii) International Trade and Government Initiatives in India (Fig. 1).

First, we have developed the call for special issue on the "Rebound to Higher Levels of Operational Excellence and Export competitiveness", and invited tscholarly articles, empirical studies, reviews and perspective papers from the 
Fig. 1 Rebound to operational excellence and export competitiveness: editorial pathway

\begin{tabular}{|c|c|c|}
\hline $\begin{array}{l}\text { Academic } \\
\text { Resourse } \\
\text { Present JGBC Special } \\
\text { issue (SI) }\end{array}$ & $\begin{array}{l}\begin{array}{l}\text { Industrial } \\
\text { Discourse }\end{array} \\
\text { Industrial and Financial News } \\
\text { Reports }\end{array}$ & $\begin{array}{l}\text { International } \\
\text { Trade \& } \\
\text { Government } \\
\text { Initiatives }\end{array}$ \\
\hline $\begin{array}{l}\text { Leading Journals' SIs on } \\
\text { Post-pandemic }\end{array}$ & Success and Failure cases & $\begin{array}{l}\text { Atma-Nirbhar Bharat- } \\
\text { Economic Resuraggence }\end{array}$ \\
\hline $\begin{array}{l}\text { Operational revival } \\
\text { (Calls and Editorials) }\end{array}$ & $\begin{array}{l}\text { Panel Discussions and } \\
\text { Interviews of Industry leaders }\end{array}$ & $\begin{array}{l}\text { Bi-/Multi-lateral } \\
\text { Initiatives }\end{array}$ \\
\hline Published Papers (SIs) & & \\
\hline
\end{tabular}

international academicians and industry leaders. With the critical double-blind review process to ensure alignment with the issue theme, eight special issue articles are selected and published online as early-cite articles. This work includes the editorial presenting the summary and alignment of each contributing paper, and refers the contributions as the initial input to this study. Similar to JGBC, many top-leading journals in the field of Technology, Operations, Services, Supply chain, Business research and competitiveness such as Journal of Operations Management, (JOM), International of Production Research (IJPR), International of Production Economies (IJPE), Production and Operations Management (POMS), OMEGA are engaged in the research on the Post-Pandemic Operational and supply chain resilience. These special issue calls and early cite articles are reviewed to benefit international scholarly viewpoint on the Operational excellence and international competitiveness of the new world order.

Second, we have studied operational resilience efforts and thereby operational competitiveness journey in the Industrial discourse. We do understand that the operational and SC resilience is ongoing phenomenon in many industries worldwide, and it may not get reflected significantly as performance indicators. We have studied various daily and weekly operational and supply chain newsfeeds, to ground our discussions with the operational and supply chain practices.

The Operational and Supply-Chain disruption is the global phenomenon, and many nationwide as well as international programs are emerging as the policy level reconfigurations. The international collaborations as well as multilateral initiatives such as QUAD, AUKUS, SAARC, BRICS, G-20 group are exploring possible ways for operational excellence in the global trades. Thirdly, we have referred the government reports, news items and secondary resources on policy initiatives and strategic decisions to establish the connect with the strategic-tactical and operational aspects of operational excellence and export competitiveness.

Operational Excellence (OE) may be visualized as a comprehensive approach to attain best-in-class performance in productivity, quality, and responsiveness across the value chain (Luz Tortorella et al., 2021). OE spans product design and development; enterprise resource; planning and control; supply chain management; manufacturing execution besides traditional business functions and also involves both soft and hard factors (related to people, processes, and technology) (Gólcher-Barguil et al., 2019). It may also be noted OE is an ongoing journey rather than a destination! (Chakraborty et al., 2020; Kulkarni et al., 2014).

\section{Academic Efforts towards Reconfiguring Operational Excellence and Export Competitiveness}

The academic efforts in reconfiguring operational excellence are studied via three inputs- (a) Special Issue calls for papers on Post-Pandemic Operations and Supply Chain Excellence of select leading academic journals, (b) Published Special issues of select journals on Post-pandemic recovery, (c) Scholarly Contributions included in JGBC-SI Rebound to Higher levels of Operational excellence and Export Competitiveness.

\section{Special Issue Calls for Papers on Post-Pandemic Operations and Supply Chain Excellence}

Many leading journals like IJPR, POMS, Supply Chain Management, Journal of Operations Management, IJOPM, OMEGA, IJPDLM, JGOSS are engaged in exploring opportunities for research interventions in excelling operations and supply chain performance. The summary of select SI calls of leading journals is tabulated in Table 1.

Apart from such listed core manufacturing and Supply Chain Operations calls, certain in the allied areas are also exploring post-pandemic aspects of business. The summary of the call is attached in appendix I: Supplementary file 1.

The exhaustive list of SIs surely points out some important points: (i) Global Disruptions in Operations and Supply Chain is a vital concern among academicians both to recover consumable supplies as well as to ensure humanitarian and medical supplies across the globe. (ii) Academicians do also agree on the ripple and bullwhip effects of localized 


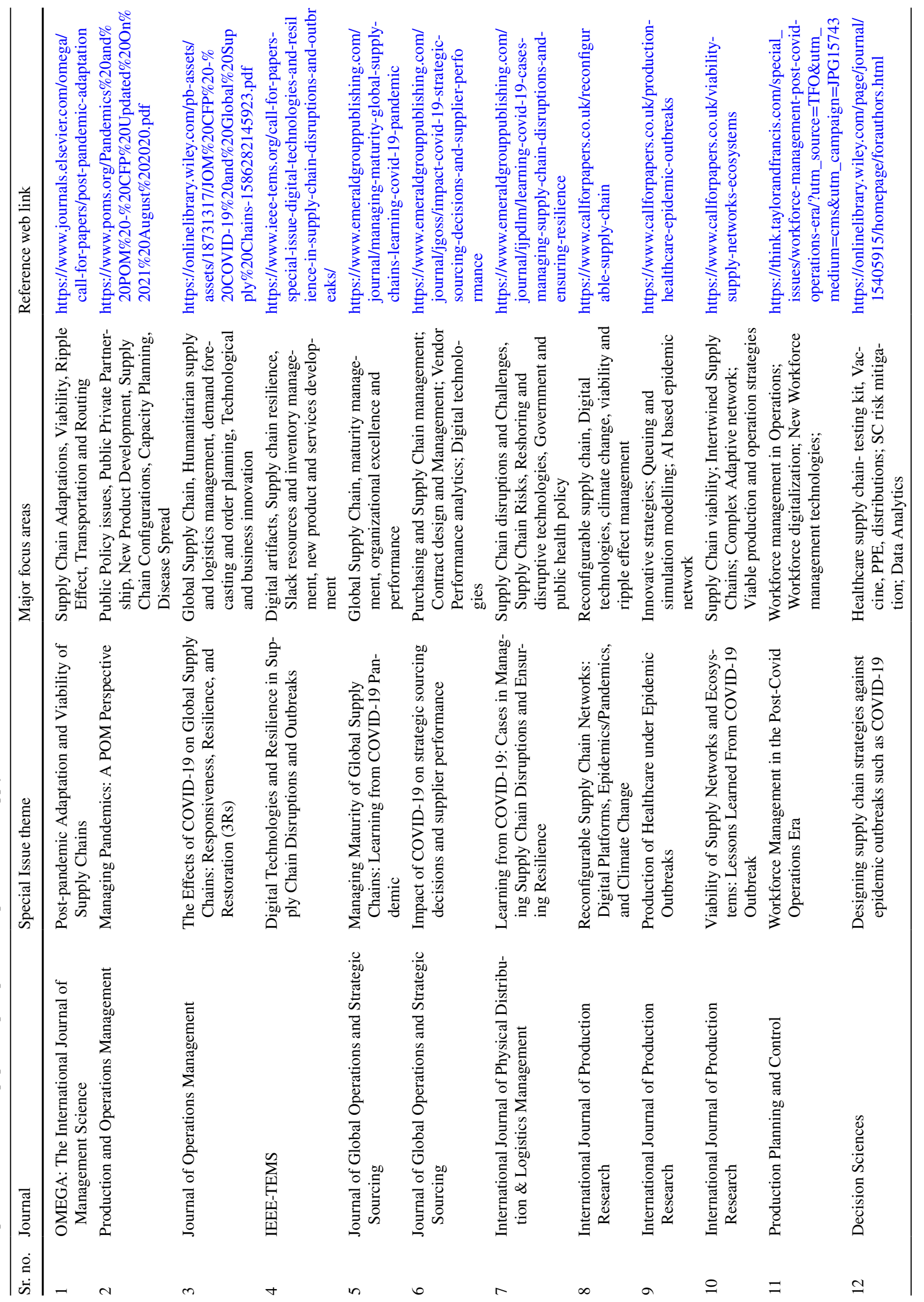




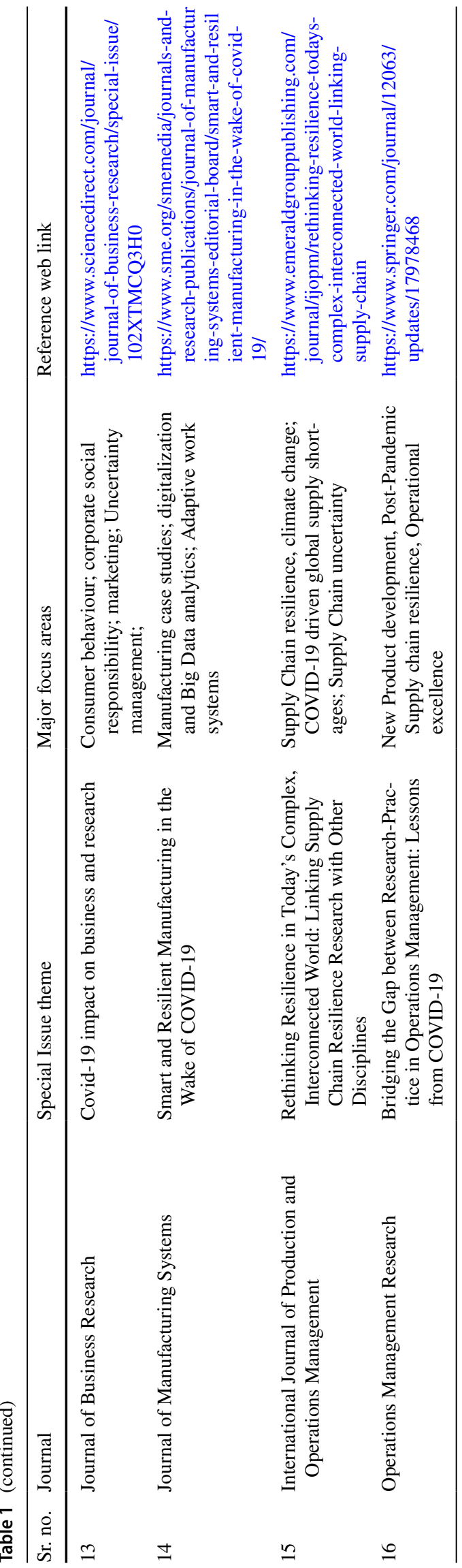

disturbances on value chain, impacting the global supply shortages. (iii) Researchers through such calls postulate Digital technologies and interconnectedness in the supply chains have the potentials to recover Operations and Supply chain performance in post-pandemic times. (iv) Reshoring and localization of supplies can nimble the complexities of supply chain. (v) Bridging gap between academic research and practice and focus more on empirical action-based research rather than just conceptualization of SC resilience is paramount.

Though these SIs are in progress, and submissions are open while writing this article (September 2021), the impact of the upcoming knowledge advancement through these calls is clear. The emerging themes and ways for possible managerial interventions are still a far to reach.

\section{Impact Publications Referring to Global SI Call}

While most of SIs while writing this article (September 2021) are in progress, some of the journals have published their SIs in advanced, giving us insights on potential knowledge treasure in rebounding operational excellence. Table 2 details the emerging themes of global SIs of select journals.

As discussed, these are early efforts of research, but some of the prominent emerging themes of research are as follows: (i) Impact of COVID-19 on supply chains, (ii) Resilience strategies for managing impacts and recovery, (iii) Role of Digital Technology for risk mitigation, (iv) Humanitarian and Healthcare Supply Chain and Logistics (v) Significance of Agility, Adaptability and Alignment (3As) of Supply Chain. Chowdhury et al., (2021) presented the systematic review on supply chain efforts on post-pandemic recovery and presented the research avenues in the emerging themes.

\section{JGBC Special Issue (SI): Rebound to Higher Levels of Operational Excellence and Export Competitiveness}

Research on operational excellence and its association with competitiveness is one of the widely discussed themes. However, on the backdrop of global supply chain disruptions, the exports and trades are heavily hampered. The operational excellence through just-in-time delivery, supply chain offshoring, network manufacturing has exposed with serious questions in pandemic times. Thus, JGBC decided to explore a special issue with the theme of Rebound to Higher levels of Operational excellence and Export Competitiveness. The aim of SI is to understand the potentials of operations and supply chains and define newer frameworks and approaches to revive operations and supply chains in post-COVID-19 times.

Hundreds of enquiries with over 35 scholarly contributions were received within the shorter span from July 2020 


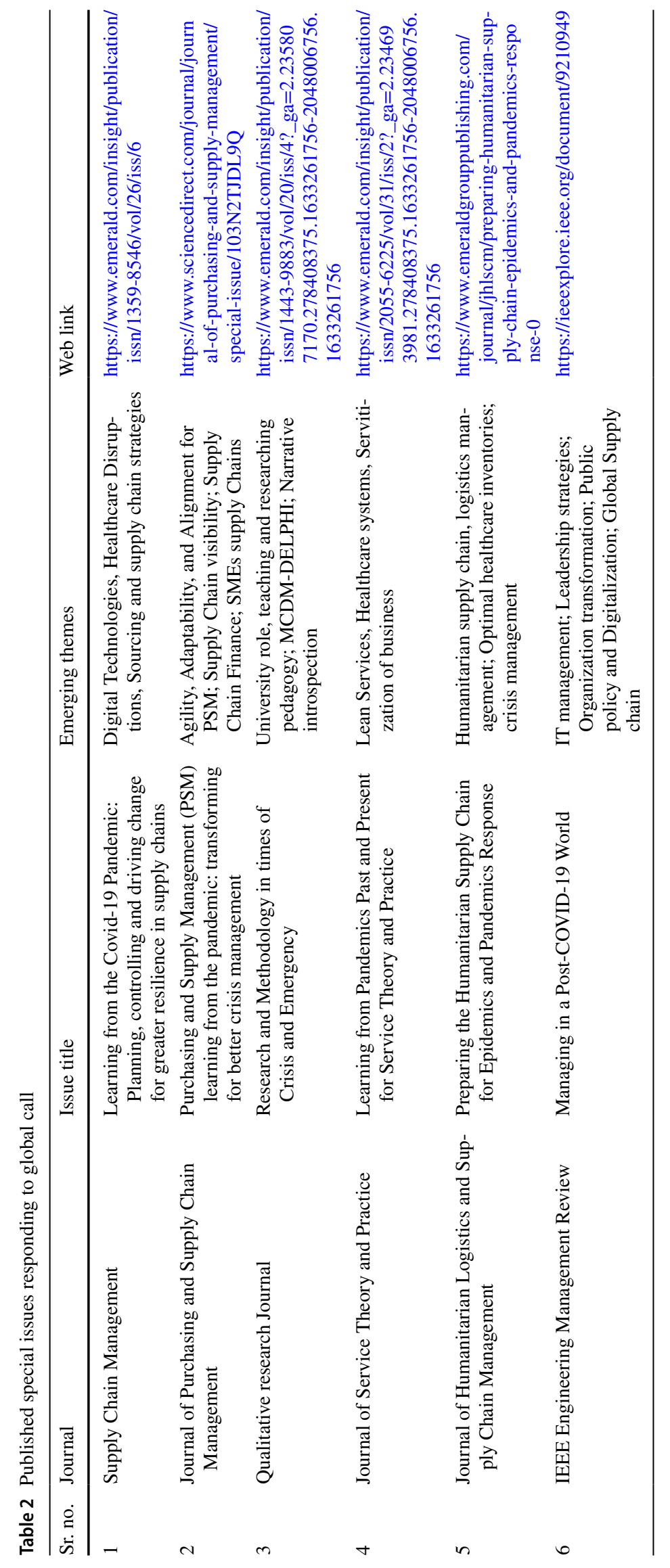


to January 2021. The enquiries and submissions arrived from the diverse research domain such as Operations, manufacturing, supply chain, sourcing, business competitiveness, healthcare services, Digital technologies. The submissions arrived from such diverse backgrounds indicating the significance of integrative efforts aligning with the theme.

The reviewers, JGBC editorial office, Guest editorial team and Editor-in-chief fast-tracked the review process and provide the rapid feedback providing authors to give ample time to re-align their revisions according to feedback. Preferably more action oriented, empirical short-length articles were selected based on contribution to theory, appropriateness of methodology, perspectives and implications.

The scope of Operations and Supply Chain includes both manufacturing as well as services industry. We strongly believe, the pandemic shall end, but the learnings to shape our futures should not be forgotten. Thus, the thrust of selecting the articles with guideway for the post-pandemic world, rather that reporting the opportunity and operational losses.

The Framework for Promotion of Medical Tourism by Vinaytosh Mishra and Mohita G Sharma highlighted the challenges of medical infrastructures in the developing countries and argued that the emerging markets such as India can be promoted for the Medical tourism in post-pandemic times. The study highlighted the reason behind the low penetration of medical tourism and explored service Quality gaps using SERVQUAL. The study presents the framework for increasing medical tourism and suggest the following drivers for service competitiveness- (i) Lean Healthcare, (ii) Quality Management System, (iii) NABH and EQAS systems, (iv) Communication and Language Skills and (v) Ease of VISA and Emigration Rules.

Sustainable Finance is one of the critical issues for the businesses in Post-COVID Era. A Decision-Making Framework for Sustainable Supply Chain Finance in Post-COVID Era, the study by Nainsi Gupta and Gunjan Soni, provided critical insights for Cash management as the priority concern in food supply chain finance using Fuzzy-AHP.

Airline industry is amongst the worst affected industries due to preventative travelling restrictions. Additionally, air transport-being the fastest mode of transportations has been proved critical in the logistics of critical medical equipment, pharmaceuticals, patients and resources. Modeling the Factors of Productivity in Airline Industry in India: A Hybrid TISM-P and Fuzzy-MICMAC Approach by Shamita Garg and Vikas Thakur model the productivity factors of airline industry and highlighted plans for excelling export competitiveness through airline productivities.

Supply Chain disruptions have not only impacted the local production networks but also cascading effects on other players of value chain. The study by Ravindra Ojha, Jones Mathews and Umashankar Venktesh, argued the potentials of downstream innovation to improvise the delivery reach with the critical insights from Indian auto sectors. This study has provided the guideway for downstream innovations through- (i) dealership sales management, (ii) service center operations and (iii) customer relationship management.

Shop floor work systems are expected to developing new approaches to increase the efficiency, agility and resilience of operations, and shop floors often find their ways through lean thinking. Lean Thinking, Logistic and Ergonomics: Synergetic Triad to Prepare Shop Floor Work Systems to Face Pandemic Situations by Tiago Alfonzo, Anabela C Alves and Paula Carneiro demonstrated the integration of lean logistics and ergonomics to reduce human-system interactions in a post-pandemic workplace through the case study.

Supply chain responsiveness and resilience is emerging as the important study theme in Post-pandemic operational themes. Technology-Driven Responsiveness in Times of COVID-19: A Fuzzy Delphi and Fuzzy AHP-Based Approach, by Chetna Chauhan, Manzoor Ul Akram. The investigation is demonstrated in food industry highlighting supply chain integration technologies, sustainable manufacturing technologies, and smart warehousing potential enablers of supply chain responsiveness.

The psychological stressors are due to fear of losing jobs, digitization change of workplaces; contamination fear and family pressures impeding operational resilience movements across the organizations. The emphatic corporate communications form the important aspects of operational recovery and crisis management. The perspective study by Prof Reeta Raina, Moving Crisis to Opportunities: A Corporate Perspective on the Impact of Compassionate Empathic Behaviour on the Well-Being of Employees, presents emerging themes of emphatic communications in post-pandemic crisis through structured interviews of apex leaderships of select global companies.

The operations at Hospitality and Hotel industry is deeply troubled with pandemic travelling and movement restrictions. Post-lockdown, the leading hotels have reconfigured their operations addressing CAB. Operational Changes and Performance Outcomes: Analysis on hotels of five Asia-Pacific countries by Arghya Ray and Lan Ma compared the operational responses of 500 leading Hotels across five Asia pacific countries, and explored the drivers of customer loyalty during the post-Covid times.

Similar to the Hotels industry, tourism sector and associated taxi aggregators have experienced the heat of the movement restrictions. Analyzing Role of E-SERVQUAL Constructs for Post-Pandemic Recovery of Indian Taxi Aggregator Services by Avadhut Arun Patwardhan and Neeraj Pandey, explored the role of E-SERQUAL constructs and suggested the remedy strategies based on efficiency, 
Table 3 Select manufacturing industries and during pandemic (Kumar et al., 2020; Madurai Elavarasan \& Pugazhendhi, 2020)

\begin{tabular}{lllll}
\hline Sr. no. & Company & Domain & Before COVID-19 Pandemic & During COVID-19 Pandemic \\
\hline 1 & Ford & Automobile Industry & Vehicles & Respirators and Ventilators \\
2 & Zara & Fashion & Apparel & Surgical masks \\
3 & Tesla & Automobile Industry & PV cells and e-vehicles & Ventilators \\
4 & Airbus & Aircraft Industry & Aircraft & Ventilators \\
5 & Bacardi & Process Industry & Alcoholic beverages & Hand Sanitizers \\
6 & Indian Ordnance factory & Defense Manufacturing & Defense equipment & Ventilators \\
7 & Gucci & Apparel & Clothing & Masks \\
8 & Dyson & Appliance manufacturing & Vacuum cleaners and Hair Dryers & Ventilators \\
9 & L'Oréal & Personal Care & Face creams and perfumes & Medical disinfectants and sanitizer gels \\
10 & Mercedes-AMH High- & Automotive Industry & Formula 1 Engines & Continuous Positive Airway Pressure \\
& performance Power- & & & (CPAP) machines \\
& trains & & Passenger cars & Ventilators \\
\hline
\end{tabular}

contact and privacy for both short and long term customer retention.

The COVID-19 pandemic has placed the unprecedented stresses on the operations and supply chains. The key points and themes reflected in our JGBC SI papers are as follows: (i) Future supply chain need to be reliable, responsive, resilient, and responsible, (ii) Top Leadership and commitment to the revival is critical in developing operational excellence, (iii) Data-driven decision making and advanced technologies can leverage the responsiveness of operations and supply chain, (iv) Healthcare, Food, Tourism, Hospitality and shop floors manufacturing are emerging as a priority sectors in the post-pandemic resilience efforts and research interventions.

\section{Industrial Discourse on Operational Excellence}

Capturing efforts of industrial discourse is majorly restricted to secondary sources such as news reports, cases, panel discussions and webinars, as a majority of work for this section is carried out under precautionary lockdown conditions. With the limited travelling and resources, how to capture industrial discourse was the key issue the editorial team faced, but then internet technology and expert discussions reported in mainstream and social media guides us the way. We have studied the some of the leading companies across the globe and compare their change in product offerings during pandemic. The summary of this exercise is presented in Table 3. No doubt, the summary reflects a snapshot of the leading worlds manufacturing companies' resilience and business support to overcome COVID-19 impact.

Responding to the extended need for personal sanitization care, Hindustan Unilever Ltd (HUL), one of the leading Fast-moving consumer good company (FMCG) launched the exclusive personal care segment with the launch of innovative disinfectant cleaners for surface, fruits and vegetables, Germ kill spray, Germ removal wipes, Germs removal detergents. Similar to such global leading companies, Indian businesses too, revamped their operations in the response to the pandemic requirements and COVID-19 Appropriate Behavior $(\mathrm{CAB})$. The changes are reflected in new products and services, advertisements and market positioning. We summarize the post-pandemic revival efforts through operations and trade in Table $4 .^{2}$

Despite various operational efforts of reconfiguring operational excellence, following critical issues requires further efforts for the levels export competitiveness: (i) Weakening demand for several products and services such as automotive, textile, Hospitality and public transportation systems, (ii) Skyrocketing demands for COVID-19 Vaccines, testing kits, medical equipment, thermal scanners, ventilators, PPE and essential food items, (iii) Failures of supplies and uncertainty in raw material supplies, (iv) Shortages and logistical bottlenecks impacting global trades, (v) Workforce productivity in safe and Hygienic bio-bubbles (Kumar et al., 2020).

\section{International Trade and Policy Decisions in India}

International trade was slowing down prior to pandemic in the first quarter of 2020, but the economic and supply chain disruption brought by COVID-19 pandemic resulted in a dramatic decline in the trade. The value of international

\footnotetext{
2 Table 4 is developed as the summary of the class-project works of Operations Management-I students of FMG 29, FM-02 and BDA-01 batch of FORE School of Management, New Delhi.
} 


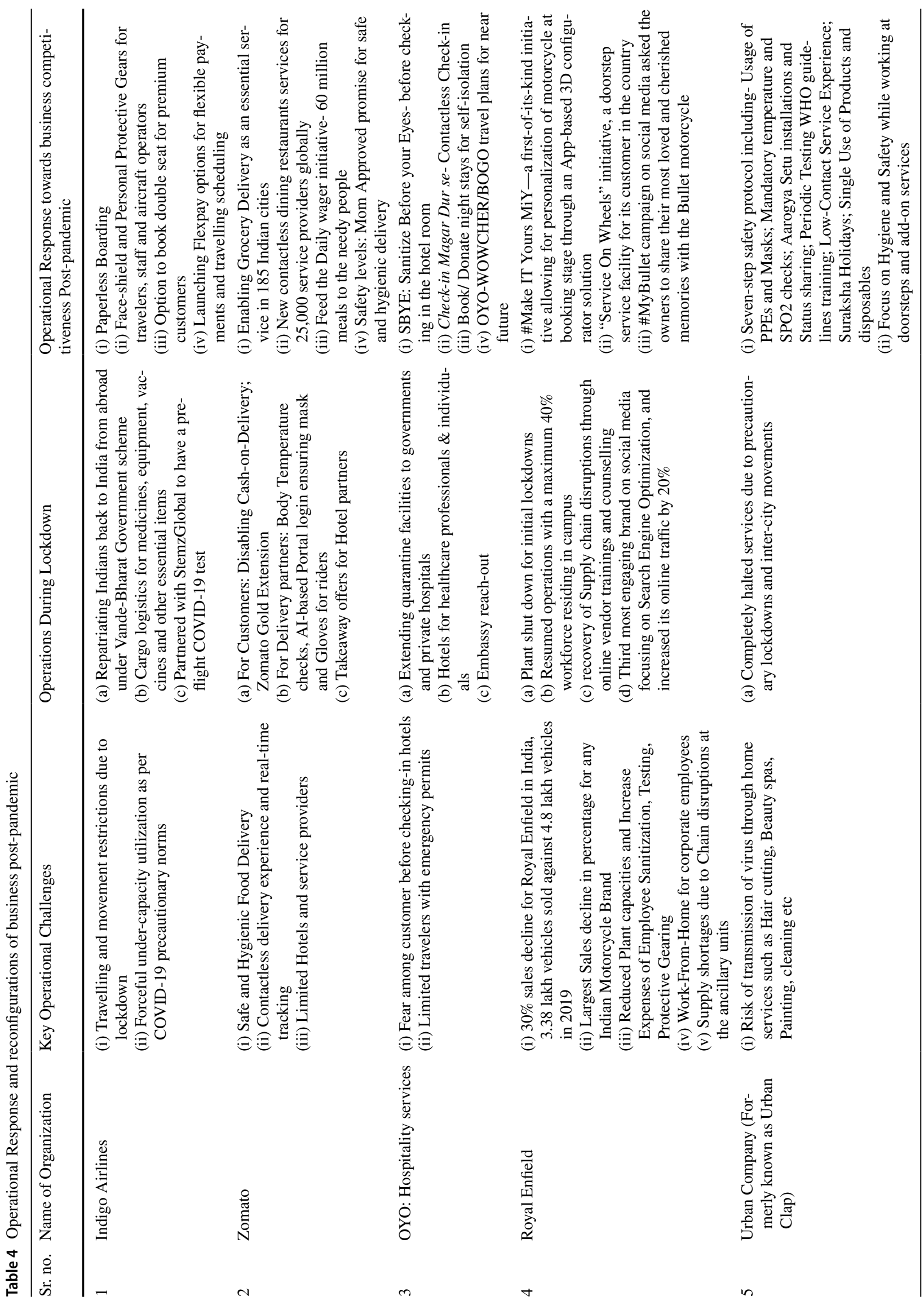


trade in goods has declined by about 5\% in Q1 2020. Experiencing unpresented decline around $27 \%$ in Q2 2020, world trade rebound to positive trends. For instance, the value of international trade in goods and services grew by about four percent quarter-over-quarter and by about ten percent yearover-year. Importantly, international trade in Q1 2021 was higher than pre-crisis levels, with an increase of about three percent relative to Q1 2019. The trade rebound of Q1 2021 continues to be driven by the strong export performance of East Asian economies (Global Trade Reports, 2021) (Global trade Report, UNCTAD/DITC/INF/2020/2; Global trade Report, UNCTAD/DITC/INF/2021/2).

\section{Global Recovery and Measures of Export Competitiveness}

With a few exceptions, trade-in major economies recovered from the fall of 2020 . However, the large quarterly increases in percentages are due to the low base for 2020 and trade in many of the major economies was still below 2019 averages. The trend of a stronger recovery for goods relative to services is common to all major economies. Table 5 depicts the imports and exports of major trading economies in Q1-2021.

It should also to be noted that the world trade records the fastest recovery than last two trade recessions (2008 and 2015). Trade in goods surpasses pre-pandemic levels, indicating the recovery of operations and supply chain across the globe. The ongoing trade recovery comprises most sectors. During Q1 2021, trade continued to rebound not only in sectors related to COVID-19 (e.g. pharmaceuticals, communication and office equipment) but also increased for most other sectors, such as textiles, minerals, apparel, machinery, road transport, other manufacturing and agro-food. In contrast, the energy sector continues to lag behind and international trade of air/water transport equipment remains well below averages. Vast negative gap between exports and imports and exports for India (e.g. contrast with Japan) indicates huge opportunities for improvement in export competitiveness for India.

\section{India: Road Ahead Through Atma-Nirbharata (Self-Reliant India)}

International companies with short-term goals, are attempting to fix the broken value chains, but for longer term, companies are exploring the ways to minimize supply chain risks and improve? resilience. Recognizing the indigenisation opportunity, in May 2020, India launched Atma-nirbhar Bharat initiative with Rs. 20 Lakh crore economic package. Despite citing it as a package amounting to $10 \%$ of GDP, the actual fiscal impact is estimated to be $1 \%$ as said by many experts. The breakup of the package is summarized in appendix II: Supplementary file1.
Table 5 Imports and exports of major trading economies in Q1-2021

\begin{tabular}{|c|c|c|c|c|}
\hline & \multicolumn{2}{|c|}{$\begin{array}{l}\text { Q1 2021- Relative to } \\
2020 \text { Average (in \%) }\end{array}$} & \multicolumn{2}{|c|}{$\begin{array}{l}\text { Q1 2021- Relative to } \\
2019 \text { Average (in \%) }\end{array}$} \\
\hline & Imports & Exports & Imports & Exports \\
\hline \multicolumn{5}{|l|}{ India } \\
\hline Goods & 45 & 26 & 10 & 7 \\
\hline Services & 14 & 2 & 2 & $3 \sqrt{5}$ \\
\hline \multicolumn{5}{|l|}{ Brazil } \\
\hline Goods & 22 & 17 & 4 & 8 \\
\hline Services & 2ళ & 2 & 31 & 15 \\
\hline \multicolumn{5}{|l|}{ Russia } \\
\hline Goods & 15 & 14 & 9 & 10 \\
\hline Services & 7 & $5 \Omega$ & 30 & 28 \\
\hline \multicolumn{5}{|l|}{ China } \\
\hline Goods & 22 & 20 & 20 & 25 \\
\hline Services & 3 & 27 & 23 & 22 \\
\hline \multicolumn{5}{|l|}{ Japan } \\
\hline Goods & 11 & 16 & $2 \sqrt{2}$ & 5 \\
\hline Services & 5 & $2 \sqrt{2}$ & $2 \sqrt{2}$ & 24 \\
\hline \multicolumn{5}{|l|}{ USA } \\
\hline Goods & 14 & 16 & 7 & 0 \\
\hline Services & 10 & 3 & 14 & 18 \\
\hline \multicolumn{5}{|c|}{ European Union } \\
\hline Goods & 13 & 14 & 1 & 6 \\
\hline Services & $1 \Omega$ & 7 & 13 & 6 \\
\hline
\end{tabular}

Table 5 is Compiled from Global trade Report, UNCTAD/DITC/ INF/2021/2. UNCTAD calculations based on national statistics. NOTE: Growth rates of Q1 relative to year averages for 2019 and 2020. Seasonally adjusted and in US dollars

The broad policy and government-driven changes emanating from COVID-19 pandemic also mean changes in operations, technology, innovations and supply chain perspectives. Such policy-wide stimulus at macro levels requires the industry levels support. With discussions with experts, industrialists, and academicians revealed that the Governments have tried a lot to fight against COVID-19, despite very poor fiscal situations in many states and even centre. Businesses now need to foster the opportunities to reboot by self or through cooperation such as through associations, rather relying excessively on government packages. However, our discussions with experts, emerged four critical challenges of Indian businesses that require policy thinking- (i) Weak Demand, (ii) Supply Chain Disruptions, (iii) Liquidity Crunch and (iv) Labour and Capacity Underutilization. Table 6 outlines the common business challenges and possible policy interventions. 
Table 6 Business challenges and proposed government interventions

\begin{tabular}{|c|c|c|}
\hline Sr. no. & Business challenges & Proposed Government Interventions \\
\hline 1 & $\begin{array}{l}\text { Weak Demand- Due to Joblessness, limited purchasing power, } \\
\text { relying on essential purchases, travelling restriction impacting } \\
\text { transport, tourism, hospitality and aviation sectors }\end{array}$ & $\begin{array}{l}\text { Demand Boosting: Through (i) Export incentives, (ii) GST Rate } \\
\text { (iii) Relaxation in tax compliances, (iv) Imposing import duties } \\
\text { to boost up local manufacturing, (v) Infrastructural projects vi) } \\
\text { Making competitive imports and explore attracting big business } \\
\text { houses }\end{array}$ \\
\hline 2 & $\begin{array}{l}\text { Supply Chain Disruptions- Shortages of materials, resources } \\
\text { resulting in the longer lead times and financial liabilities }\end{array}$ & $\begin{array}{l}\text { Supply stimulus through- (i) Lockdown Relaxation in non-hot } \\
\text { spot areas, (ii) Key players (raw materials suppliers, buyers, } \\
\text { technology providers and logistics providers) developments for } \\
\text { each value chain, (iii) Ease of Doing business and exporting, (iv) } \\
\text { Boost-up to exports and port clearances, (v) Use of digital tech- } \\
\text { nologies to identify, execute and resolve supply chain challenges. } \\
\text { vi) Tangible actions on 'Circular economy' initiatives (Sahenem } \\
\text { et. Al, 2019) }\end{array}$ \\
\hline 3 & $\begin{array}{l}\text { Liquidity Crunch- Increasing overheads, Loan interest liabilities } \\
\text { for MSMEs, lower demands and sales }\end{array}$ & $\begin{array}{l}\text { Liquidity support through (i) lowering duties, taxes and GST rates, } \\
\text { providing quick refund of taxes and immediate release of incen- } \\
\text { tives under the industrial and sectoral policies, (ii) Subsidies on } \\
\text { interest rates, (iii) Waiver on fixed overheads of electricity, water, } \\
\text { housing taxes for initial months }\end{array}$ \\
\hline 4 & Labour and Capacity Underutilization & $\begin{array}{l}\text { Capacity utilizations is the Function of Demand boost-up and sup- } \\
\text { ply stimulus. Importance of localizing the supply sources, focus } \\
\text { on foreign investments, supply chain infrastructure and employ- } \\
\text { ment generations. Initiation of much awaited labour reforms } \\
\text { towards enhancing labour productivity }\end{array}$ \\
\hline
\end{tabular}

\section{Recommendations and Way Forward}

Rebound to Higher Levels of Operational Excellence and Export competitiveness is a continual journey. The positive sides of the post-pandemic recovery can be summarized as follows: (i) Faster recovery than the earlier two recessions of 2008 and 2015. (ii) Efficacy of Vaccines and thereby panic relaxation, (iii) Focus of relying on reshoring and nearshoring trends, (iv) Multilateral efforts including academic, industrial and policy-level initiatives towards operational excellence. We propose the following recommendation based on our efforts at JGBC special issue Rebound to Higher Levels of Operational Excellence and Export competitiveness.

\section{Recommendations for Academic Discourse}

Suggested Topics for Further Research: (Studies cited after each directive can assist researchers to understand the research context better.)

- Analyzing the Covid-19 pandemic impact of supply chain disruption to plan the recovery. Post pandemic Operations and Supply chain research can be directed with four basic sub themes- (a) Impacts of the COVID-19 pandemic on supply chains, (b) Resilience Strategy for mitigation and recovery, (c) Role of technologies for supply chain resilience, (d) Supply Chain sustainability and environmental consciousness (Chowdhury et al., 2021; Kumar et al., 2020).

- Research on the challenges, enablers and barriers of reshoring and nearshoring practices (Barbieri et al., 2020).

- Dedicated empirical research on cascading effects, bullwhip and ripple effects in supply chains with special reference to MSMEs and unorganized sectors (Ivanov \& Dolgui, 2021b; Li et al., 2020) (Dolgui \& Ivanov, 2021).

- Exploring the utility of Operation Research tools and techniques in post-pandemic revival of manufacturing, planning, control, and supply chain issues (Choi, 2021).

- Questioning single time best practices such as Lean, in the volatile and uncertain times and explore next generation best practices in relation to complex supply networks, strategy implementations and people management (Micheli et al., 2021).

- Exploring Industry 4.0 technologies such as Additive manufacturing; Augmented reality, virtual reality and holography; Cloud computing, big data, and 5G, Robotics; Machine learning, AI and IoT; Blockchain and circularity practices to develop supply chain resilience (Belhadi et al., 2021; Kamble et al., 2019). The digitally enabled technologies and approaches, such as Industry 4.0, smart manufacturing, the cloud, AI, and the Internet of Things (IoT) have acted as enablers in achieving OE. It will be interesting to see the connect between the deployment of these enablers for export competitiveness and the business performance (through financial measures). 
- Advanced OR methods such as Game theory, Mixed Integer Programming (MILP), AI/ML approaches exploring Operations and Supply Chain Challenges (Nagurney, 2021).

- Learning from COVID-19 Pandemic experience and preparation for next disruptions (Flynn et al., 2021) using actor-focused approaches such as SAP-LAP (Momaya, 2020) to boost export competitiveness and sustainability.

- Focus on research enabling the development of economic-ecological-social sustainable and resilient supply chains incorporating multidisciplinary research (Sarkis, 2020)

- Empirical and Action oriented research rather than focusing on theoretical conceptualization (Remko, 2020).

\section{Teaching Guidelines}

- Updating curriculums of traditional Operations Management, supply chain management, Technology Management and Project Management with pragmatic challenges of new normal.

- Hand-on working by college students to experience / understand / contribute to the community / social issues to have more hostess decision-making approach.

- Use of innovative pedagogy in sensitizing students about the challenges and opportunities both in cyber and physical world.

- Focus on Building Leadership for tomorrow-technology driven, business process reimaging / remapping, talent retention \& upgradation, learning organization and new employee engagement approaches

- Triggering practice and project-based approach in comprehensive evaluation focusing on developing enlightening mindsets to resolve crisis.

- Frequent fact-checks on competitiveness indicators (For instance. World Competitiveness index) to develop future managers to benchmark, analyze and act https://www. imd.org/centers/world-competitiveness-center/rankings/ world-competitiveness/.

\section{Recommendation for Managers and Practitioners}

- Thinking beyond cost-competitiveness, building dynamic capability in operations and supply chains, Human Resource Management, Finances, Management of Technology or Innovation (MoT).

- Appreciation of human behavior and human-centric approaches while implementing digital technologies.

- New Product and services development for the essential items and thereby pursuing Operational Excellence (OE).

- Evolving Performance evaluation and improvement systems linking measures of operational excellence (e.g. Product Cost, Defect Rate, Delivery Speed and
Dependability, Inventory Turns, Return On Investment, New Product Developed) with International competitiveness (e.g. FOREX earnings, Logistics Performance Indicators (LPI), export shares).

- Integration of Digital manufacturing, Additive manufacturing, digital technologies such as AI, 3D printing, Robots, Cyber-physical systems, Blockchain, for the production of goods towards developing Smart Factories.

- Developing distributed Supply chain network satisfying triggered demand for online contactless deliveries.

- Consideration of importance of flexibility, shorter response times and dependable deliveries as the competitive priorities of a new order.

- Revisiting operational excellence practices such as Lean, TQM in the relevance of Post-COVID-19 crisis

- Project Operations in Post-pandemic times considering resilience in the projects

- De-risking of supply chain with near or local sourcing

- Reactive risk mitigation to proactive risk reduction approach

- Deploying social media engaging campaign evaluate the behaviour and consumption trends of customers.

- Develop a manufacturing network strategy fit for alternative sourcing options for raw material, suppliers and logistics service providers etc. for mitigating such disruptions (Kumar et al., 2020).

- Planning and mitigation for supply decisions in terms of capacity, workforce, inventory etc. to ensure smooth supply from customer's perspectives with model and data-driven decision making (Ivanov \& Dolgui, 2021a).

- Incorporating digital technologies develop end-to-end visibility, collaboration, responsiveness, agility, and resilient supply chain and logistics.

- Enriching supplier segmentation and adopting multiple local suppliers

- Value chain analysis and management to ensure seamless co-ordination and SC flows of Material, Capital and Information.

- Design and development of distribution centers and warehouses with ensuring lean, ergonomics and logistical principles

- Analysis and resolution of trade-offs among Resilient, Adaptive and sustainable supply chains

- Diagnose patterns of competitiveness journey, major gaps or problems and analyze to identify root causes (e.g. (Momaya et al., 2017)). Explore actions at interfaces of functional areas (e.g. R\&D, operations, SC, finance (Haldar et al., 2016)) and export competitiveness.

- Creativity and Innovation-driven ecosystem with effective product and talent management system (Haleem et al., 2018) Chandrashekar and Subrahmanya (2017). 


\section{Recommendations for Policy Makers}

- Boost-up packages, investments and support for MSMEs and unorganized sectors such as initiatives like National Manufacturing Competitiveness Council (NMCC), MUDRA loan, Make-In-India, Digital-India; and Startup India.

- Evolving a new National Manufacturing Policy (NMP2.0) laying high importance to circular economy, technology interventions, Talent management, smart factories,

- Reforms at Technical educational policies with Diploma and other vocational education, labour reform, revamp export policies, ease-of-doing business, etc.

- Revisions of Global and National Manufacturing policies in accordance with competitiveness requirements in the new normal business order.

- Evolving new dimensions of competitive in view of "new normal"

- International and national Risk Mitigation and Uncertainty forums to discuss, debate and resolve global supply chain challenges.

- Co-ordination amongst supply chain players, academicians, government regulatory bodies and investors

- Boosting up Healthcare infrastructure, medical facilities, pharmaceutical supply chains at the policy priority.

- Promotion of Real-time production and consumption patterns and big-data-driven approaches towards humanitarian aids.

The linkage of operational excellence (OE) and export competitiveness is vital. The pursuit of Competing through operational excellence requires understanding with respect to two basic facets- (i) $\mathrm{OE}$ requires collaborative and cooperative efforts from all stakeholders, (ii) $\mathrm{OE}$ demands resilience (Resnick, 2021).

\section{(i) OE Requires Collaborative and Cooperative Efforts from all Stakeholders}

$\mathrm{OE}$ assumes continuous improvement. This calls for careful planning, and a team effort. This typically involves collaboration and cooperation across the value chain. This may be achieved through digitalization enabling seamless integration across various processes from design, development, engineering to operations (Chakraborty et al., 2020; Kulkarni et al., 2014). How well companies design, develop, engineer, source, make, distribute, and enable reverse flow and manage their assets will result in successful executions. We must remember that close and active collaboration across people, processes, technologies, and organizations play a crucial role in achieving OE (Luz Tortorella et al., 2021). The soft factors (such as team efforts, manufacturing leadership, and communication across the chain.) are also vital along with hard factors related to new generation technologies (especially in view of Industry 4.0 architecture). Thus, emphatic communications across the stakeholders are vital as highlighted in the perspective study Raina (2021), included in this special issue.

\section{(ii) OE Demands Resilience}

One of the typical objectives of a company engaged in pursuit of OE, especially after Covid-19, is to ensure resilient operations that improve its capabilities to overcome a variety of risks, such as disruptions in supply/distribution, disruptions in manpower availability, enhanced cybersecurity threats, new environmental regulatory compliance (in view of climate change!), and plant and personnel safety requirements, like shifting to remote monitoring and control operations or in-plant partitioning and social distancing. All of these demands operational resilience solutions. The solutions must evolve keeping the context in mind. Resilience is required to overcome disruptive forces. Resilience keep the business ticking with vibrancy (Resnick, 2021).

The pursuit of OE is like chasing a moving target. The performance benchmarks are continuously changing. This is due to a variety of factors - changing technology (especially digital technology) in view of the pandemic, changing regulatory compliance requirements (especially in view of climate change), huge considerations for safety and security of both people and systems (Gólcher-Barguil, 2019). The path to OE must consider the customer needs and business environment (Sahenem et. al., 2019). These will change over time, with the COVID-19 and major supply chain interruptions being recent examples of business disruptions. To meet these changing needs, the OE goals will also invariably change to respond and adapt over time. Failure to do so will result in lagging, rather than leading, operational, and business performance. An organisation's challenges extend beyond the production domain, covering the entire value chain with constraints that constantly change and evolve over time.

Any shortfall in meeting the expectations/aspirations may lead to underperformance of the organisation thereby having a risk of losing the market. An organization must be able to sense and respond to the changing signals coming from both the external as well as internal environment. Continuous environmental scanning is necessary to read the market dynamics. This will lead to meaningful action. A conscious and deliberate Operations strategy in place will facilitate in steering the challenges in VUCA (Volatile, Uncertain, Complex and Ambiguous) environment.

During the COVID-19 surge and the subsequent precautionary lockdowns, panic buying and sticking on inventories emerged as way-out to match up the shortages, hoping the scenario would be resolved in a shorter duration. Many global 
leading companies had no plans to redesign or realign their businesses, thinking beyond the regularizing material supplies. Slowly, industries, and policymakers are acting upon the challenges of difficult times and unifying efforts towards Rebound to Higher Levels of Operational Excellence and Export competitiveness. Hopefully, the research opportunities inspired by a special issue can inspire the flurry of applied research and motivated practices to enhance operational excellence and export competitiveness of the new world order.

Supplementary Information The online version contains supplementary material available at https://doi.org/10.1007/s42943-021-00043-7.

Acknowledgements Authors would like to thank all the contributing authors, reviewers, JGBC editorial team and Dr. Kirankumar S. Momaya, editor-in-chief, JGBC for their immense contributions to this special issue. The infrastructural support provided by the FORE School of Management, New Delhi in completing this paper is gratefully acknowledged. Authors also thank Operations Management-I students of FMG 29, FM-02 and BDA-01 batch of FORE School of Management, New Delhi for their active participation in this research work.

Funding There is no funding receive for conducting this research.

Data availability Not Applicable.

\section{Declarations}

Conflict of interest There are no conflicts of interest to declare.

\section{References}

Barbieri, P., Boffelli, A., Elia, S., Fratocchi, L., Kalchschmidt, M., \& Samson, D. (2020). What can we learn about reshoring after Covid-19? Operations Management Research, 13(3-4), 131-136. https://doi.org/10.1007/s12063-020-00160-1

Belhadi, A., Kamble, S., Jose, C., Jabbour, C., \& Gunasekaran, A. (2021). Manufacturing and service supply chain resilience to the COVID-19 outbreak: Lessons learned from the automobile and airline industries. Technological Forecasting \& Social Change, 163, 120447. https://doi.org/10.1016/j.techfore.2020.120447

Chakraborty, S., Sharma, A., \& Vaidya, O. S. (2020). Achieving sustainable operational excellence through IT implementation in Indian logistics sector: An analysis of barriers. Resources, Conservation and Recycling, 152, 104506. https://doi.org/10.1016/j. resconrec.2019.104506

Chandrashekar, D., \& Subrahmanya, M. H. (2017). Does patent activity affect firm-level innovation and firm performance in a cluster? An evidence from Bengaluru high-tech manufacturing cluster. International Journal of Global Business and Competitiveness, 12(1), $13-24$.

Choi, T. M. (2021). Fighting against COVID-19: What operations research can help and the sense-and-respond framework. Annals of Operations Research. https://doi.org/10.1007/ s10479-021-03973-w

Chowdhury, P., Kumar, S., \& Kaisar, S. (2021). COVID-19 pandemic related supply chain studies: A systematic review. Transportation Research Part E, 148(2021), 102271. https://doi.org/10. 1016/j.tre.2021.102271
Deshmukh, S. G., \& Haleem, A. (2020). Framework for manufacturing in post-COVID-19 world order: An Indian perspective. International Journal of Global Business and Competitiveness, 15(1), 49-60. https://doi.org/10.1007/s42943-020-00009-1

Dolgui, A., \& Ivanov, D. (2021). Ripple effect and supply chain disruption management: New trends and research directions. International Journal of Production Research, 59(1), 102-109. https://doi.org/10.1080/00207543.2021.1840148

Flynn, B., Cantor, D., Pagell, M., Dooley, K. J., \& Azadegan, A. (2021). Managing supply chains beyond Covid-19-Preparing for the next global mega-disruption. Journal of Supply Chain Management, 57(1), 3-6. https://doi.org/10.1111/jscm.12254

Global Trade Reports (2021). United Nations Conference on Trade and Development (UNCTAD), retrieved October 10, 2021, from https://unctad.org/publications-search?f $\% 5 \mathrm{~b} 0 \% 5 \mathrm{~d}=$ product $\%$ 3A 1572

Gólcher-Barguil, L. A., Nadeem, S. P., \& Garza-Reyes, J. A. (2019). Measuring operational excellence: An operational excellence profitability (OEP) approach. Production Planning \& Control, 30(8), 682-698. https://doi.org/10.1080/09537287.2019.1580784

Haldar, A., Rao, S. N., \& Momaya, K. S. (2016). Can flexibility in corporate governance enhance international competitiveness? Evidence from knowledge-based industries in India. Global Journal of Flexible Systems Management, 17(4), 389-402. https://doi.org/ 10.1007/s40171-016-0135-3

Haleem, A., Kumar, S., \& Luthra, S. (2018). Flexible system approach for understanding requisites of product innovation management. Global Journal of Flexible Systems Management, 19(1), 19-37. https://doi.org/10.1007/s40171-017-0171-7

Ivanov, D., \& Dolgui, A. (2021a). A digital supply chain twin for managing the disruption risks and resilience in the era of Industry 4.0. Production Planning and Control, 32(9), 775-788. https://doi.org/ 10.1080/09537287.2020.1768450

Ivanov, D., \& Dolgui, A. (2021b). OR-methods for coping with the ripple effect in supply chains during COVID-19 pandemic : Managerial insights and research implications. International Journal of Production Economics, 232(2021), 107921. https://doi.org/10. 1016/j.ijpe.2020.107921

Kamble, S., Gunasekaran, A., \& Arha, H. (2019). Understanding the Blockchain technology adoption in supply chains-Indian context. International Journal of Production Research, 57(7), 2009-2033. https://doi.org/10.1080/00207543.2018.1518610

Kulkarni, S. D., Dhake, R. J., Raut, R. D., \& Narkhede, B. E. (2014). Achieving operational excellence through integrated approach of lean manufacturing and TPM methodology in mechanical cluster line: A case study. International Journal of Global Business and Competitiveness, 9(1), 15-31.

Kulkarni, S., Verma, P., \& Mukundan, R. (2019). Assessing manufacturing strategy definitions utilising text-mining. International Journal of Production Research, 57(14), 4519-4546. https://doi. org/10.1080/00207543.2018.1512764

Kumar, A., Luthra, S., Mangla, S. K., \& Kazançoğlu, Y. (2020). COVID-19 impact on sustainable production and operations management. Sustainable Operations and Computers, 1(May), 1-7. https://doi.org/10.1016/j.susoc.2020.06.001

Li, Y., Chen, K., Collignon, S., \& Ivanov, D. (2020). Ripple effect in the supply chain network: Forward and backward disruption propagation, network health and firm vulnerability. European Journal of Operational Research, 291(January), 1117-1131. https://doi. org/10.1016/j.ejor.2020.09.053

Luz Tortorella, G., Cauchick-Miguel, P. A., Li, W., Staines, J., \& McFarlane, D. (2021). What does operational excellence mean in the Fourth Industrial Revolution era? International Journal of Production Research. https://doi.org/10.1080/00207543.2021. 1905903 
Madurai Elavarasan, R., \& Pugazhendhi, R. (2020). Restructured society and environment: A review on potential technological strategies to control the COVID-19 pandemic. Science of the Total Environment, 725, 138858. https://doi.org/10.1016/j.scitotenv. 2020.138858

Micheli, P., Johnson, M., \& Godsell, J. (2021). How the Covid-19 pandemic has affected, and will affect, operations and supply chain management research and practice. International Journal of Operations and Production Management, 41(6), 773-780. https:// doi.org/10.1108/IJOPM-06-2021-902

Momaya, K. S. (2020). Return from COVID-19: thinking differently about export competitiveness and sustainability. International Journal of Global Business and Competitiveness, 14(1), 1-10. https://doi.org/10.1007/s42943-019-00002-3

Momaya, K. S., Bhat, S., \& Lalwani, L. (2017). Institutional growth and industrial competitiveness: Exploring the role of strategic flexibility taking the case of select institutes in India. Global Journal of Flexible Systems Management, 18(2), 111-122. https://doi. org/10.1007/s40171-016-0144-2

Nagurney, A. (2021). Supply chain game theory network modeling under labor constraints: Applications to the Covid-19 pandemic. European Journal of Operational Research. https://doi.org/10. 1016/j.ejor.2020.12.054

Resnick, C. (2021). Operational Excellence (OpX) Achieved by Companies That ARE Operationally Resilient. ARC Web. Retrived on November 2, 2021 from https://www.arcweb.com/industry-bestpractices/operational-excellence-opx-achieved-companies-opera tionally-resilient

Sarkis, J. (2020). Supply chain sustainability: Learning from the COVID-19 pandemic. International Journal of Operations \& Production Management, 41(1), 63-73. https://doi.org/10.1108/ IJOPM-08-2020-0568

Sehnem, S., Jabbour, C. J. C., Pereira, S. C. F., \& de Sousa Jabbour, A. B. L. (2019). Improving sustainable supply chains performance through operational excellence: Circular economy approach. Resources, Conservation and Recycling, 149, 236-248. https:// doi.org/10.1016/j.resconrec.2019.05.021

Simchi-Levi, D. (2020). Three Scenarios to Guide Your Global Supply Chain Recovery. Mit Sloan Management Review, April, 1-11. https://sloanreview.mit.edu/article/three-scenarios-to-guide-yourglobal-supply-chain-recovery/

van Remko, H. (2020). Research opportunities for a more resilient post-COVID-19 supply chain-closing the gap between research findings and industry practice. International Journal of Operations and Production Management, 40(4), 341-355. https://doi. org/10.1108/IJOPM-03-2020-0165

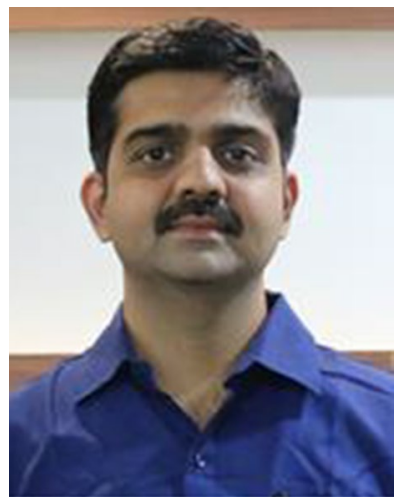

Sourabh D. Kulkarni is working as an Assistant Professor in the Quantitative Techniques and Operations Management (QTOM) area, at FORE School of Management, New Delhi. Prior joining academia, Sourabh has completed his Doctoral research in Industrial Engineering and Manufacturing Systems from NITIE, Mumbai. His research and teaching interests include Manufacturing Strategy, Lean Manufacturing, Digital
Manufacturing, Worksystem Design, Business Competitiveness. Prof Sourabh is corresponding author of this editorial and can be contacted at sourabh.kulkarni@fsm.ac.in ORCID id: https://orcid.org/ 0000-0001-7058-3502.

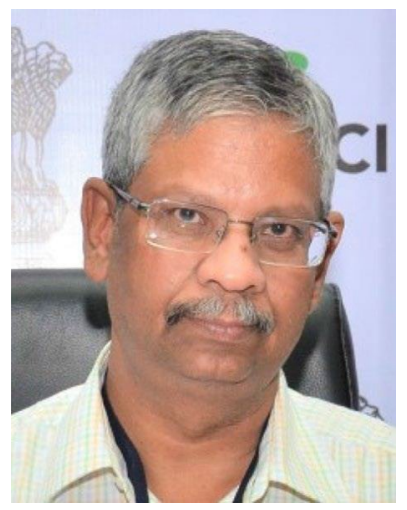

S. G. Deshmukh is a professor in the Mechanical Engineering Department of IIT Delhi. His areas of interests include manufacturing competitiveness, quality, and modeling. He has more than 30 years of teaching and research experience. He is on the editorial board of several international journals. He is a member of ISME, IIIE, ASI, and QCFI. ORCID id: https://orcid. org/0000-0002-7043-6948.

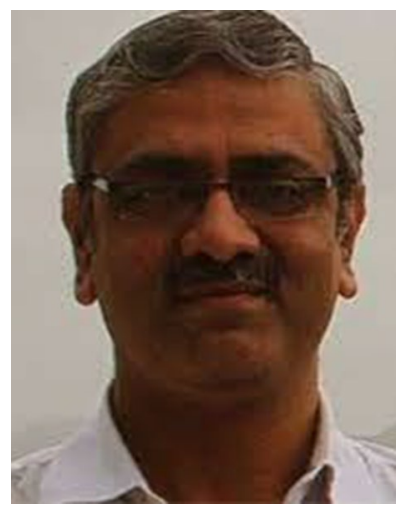

Vivek V. Khanzode is currently working as an Associate Professor in Industrial Engineering and Manufacturing Systems at the National Institute of Industrial Engineering (NITIE), Mumbai. He holds M.Tech. and Ph.D. in Industrial Engineering from IIT Kharagpur. Over the last two decades, he has worked with several industries to improve their manufacturing and logistics competitiveness. His research interests include Worksystem Design, Human-Machine Interactions, Lean Manufacturing and Warehousing, and Additive Manufacturing. He can be reached atvkhanzode@nitie.ac.in, ORCID id https://orcid.org/ 0000-0001-6206-5019.

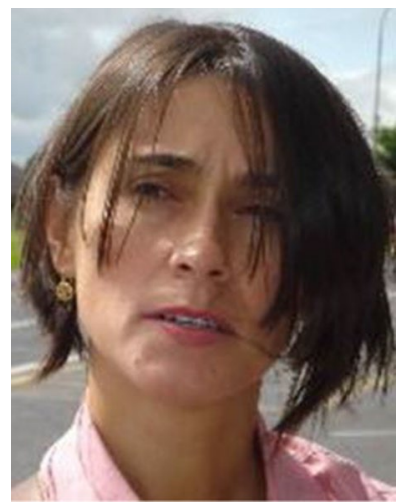

Anabela C. Alves is Assistant Professor at the Department of Production and Systems Engineering of the University of Minho (UM) and affiliated on ALGORITMI Centre, Portugal. She holds a PhD in Production and Systems Engineering. Her main research interests are in the areas of Production Systems Design and Operation; Lean Production and Lean Education; Production Planning and Control, and Engineering Education. ORCID: https://orcid.org/0000-0002-2926 $-4187$. 